\title{
PERILAKU LANSIA DALAM UPAYA PENANGGULANGAN HIPERTENSI DI WILAYAH KERJA PUSKESMAS PERTIWI KOTA MAKASSAR
}

\section{Elderly Behavior Towards An Effort To Prevent Hypertension In The Workplace Of Puskesmas Pertiwi Makassar}

\author{
Yustinus Hardianto Bulu', Rama Nur Kurniawan $K^{2}$, Ivan Wijaya ${ }^{3}$ \\ Fakultas Kesehatan Masyarakat Universitas Pancasakti Makassar
}

Korespondensi : yustinushbulu@gmail.com

\begin{abstract}
ABSTRAK
Hipertensi adalah salah satu penyakit tekanan darah tinggi yang paling sering diderita lansia. Penyakit hipertensi merupakan suatu keadaan dimana tekanan darah mencapai diatas $140 \mathrm{mmHg}$ dan tekanan diastolic diatas $90 \mathrm{mmHg}$. Berdasarkan data Puskesmas Pertiwi Kota Makassar tahun 2020 terdapat kasus hipertensi sebanyak 50 orang yang mengalami penyakit hipertensi dan dikategorikan lansia dan bukan lansia. Jumlah lansia yang mengalami penyakit hipertensi sebanyak 28 orang. Tujuan penelitian mengetahui perilaku lansia dalam upaya penanggulangan penyakit hipertensi di wilayah kerja puskesmas pertiwi Kota Makassar. Penelitian ini menggunakan metode kualitatif dengan pendekatan studi kasus. Teknik pengumpulan data menggunakan metode observasi, wawancara mendalam dengan menggunakan handphone sebagai alat perekam. Penentuan subjek penelitian dengan teknik purposive sampling dengan kriteria yaitu masyarakat penderita hipertensi, pernah berobat di Puskesmas Pertiwi Kota Makassar dan bersedia di wawancarai. Pengetahuan informan tentang penyebab hipertensi diakibatkan karena kurang mengonsumsi air putih. Dampak dari hipertensi dapat menyebabkan penyakit jantung. Cara meminimalisir dampak hipertensi dengan cara mengonsumsi sayur-sayuran dan sering berolahraga. Keyakinan penanggulangan penyakit hipertensi dilakukan dengan mengonsumsi daun klorifil, obat amlodipin, srikaya dan mentimun, vitamin menurunkan hipertensi. Dapat disimpulkan bahwa konsumsi sayur-sayuran dan sering berolah raga dapat mengurangi dampak hipertensi, serta dianjurkan kepada penderita hipertensi agar lebih meningkatkan konsumsi air putih.
\end{abstract}

Kata kunci : Perilaku lansia, penanggulangan hipertensi

ABSTRAK

Hypertension is one of high blood pressure that always happens to the elderly. Hypertension is a condition when the systolic blood pressure upper $140 \mathrm{mmHg}$ and diastolic blood pressure upper 90 $\mathrm{mmHg}$ There were 50 elderly patients and 28 non-elderly patients who suffered from hypertension Based on data from Puskesmas Pertiwi Makassar 2020. Objective Aims to know the elderly behavior towards an effort to prevent hypertension in the workplace of Puskesmas Mamajang Makassar. Used a qualitative method with a study case approach. Data collected with the observation method. An In-depth interview using a handphone as a recorder. Subject research using purposive sampling with criteria community who suffer from hypertension.had been treated at Puskesmas Pertiwi Makassar and willing to interview.Informant knowledge about the cause of hypertension is not consuming enough water. The impact of hypertension is can cause heart disease. The impact of hypertension can minimize by consuming vegetables and exercise. Some people believe hypertension can be prevented by consuming chlorophyll, amlodipine, srikaya (one kind of fruit), cucumber, and vitamins. It can be concluded that the consumption of vegetables and exercise often can reduce the impact of hypertension, and it is recommended to people with hypertension to further increase the consumption of water.

Keywords : Elderly Behavior, Prevent of Hypertension. 


\section{PENDAHULUAN}

Hipertensi sering juga diartikan sebagai suatu keadaan dimana tekanan darah sistolik lebih dari $120 \mathrm{mmHg}$ dan tekanan diastolik lebih dari $80 \mathrm{mmHg}$ Tekanan darah tinggi atau Hipertensi adalah suatu peningkatan tekanan darah didalam arteri. Secara umum, hipertensi merupakan suatu keadaan tanpa gejala, dimana tekana yang abnormal tinggi didalam arteri menyebabkan meningkatnya resiko terhadap stoke, aneurisma, gagal jantung, serangan jantung dan kerusakan ginjal. Pada hipertensi sistolik terisolasi, tekanan sistolik mencapai 140 $\mathrm{mmHg}$ atau lebih, tetapi tekanan diastolik kurang dari $90 \mathrm{mmHg}$ dan tekanan diastolik masi dalam kisaran normal. Hipertensi ini sering ditemukan pada usia lanjut. Sejalan dengan bertambahnya usia, hampir setiap orang mengalami kenaikan tekanan darah. Tekanan sitolik terus meningkat sampai usia 80 tahun dan tekanan diastolik terus meningkat sampai usia 55-60 tahun, kemudian berkurang secara perlahan atau bahkan menurun drastis8. Lansia yang mengalami gangguan hipertensi dapat mempengaruhi keseimbangan tubuh lansia. Semakin tinggi usia lansia, maka rentan postur tubuh akan terjadi keseimbangan yang buruk terhadap lanjut usia. (Kurniawan and Sulaiman, 2019).

Menurut (WHO, 2013 dalam Paisey, 2017) Hipertensi adalah kekuatan darah untuk melawan tekanan dinding arteri ketika darah dipompa oleh jantung ke seluruh tubuh.
Hipertensi adalah kondisi peningkatan persisten tekanan darah pada pembuluh darah vascular. Semakin tinggi tekanan darah maka semakin keras jantung bekerja. Tekanan darah dapat dibagi menjadi beberapa kategori menurut laporan the Eighth Joint National Committee (JNC 8), yaitu normal (di bawah 120/80 mmHG), prahipertensi (dari 120/80 mmHG sampai 139/89 mmHG), hipertensi tingkat I (dari 140/90 mmHG sampai 159/99 mmHG), hipertensi tingkat II (melebihi 160/100 mmHG).

Menurut WHO (World Health Organization) di seluruh dunia sekitar 972 juta orang atau $26,4 \%$ orang di seluruh dunia mengidap hipertensi. Dari 972 juta pengidap hipertensi, 333 juta berada di negara maju dan 639 sisanya berada di negara berkembang, termasuk Indonesia juga menempati peringkat ke-2 dari 10 penyakit terbanyak (Kurniawan and Sulaiman, 2019)

Prevalensi hipertensi di Indonesia berdasarkan hasil data Riskesdas 2018 berdasarkan karakteristik pada usia 18-24 tahun dengan jumlah penderita hipertensi sebanyak $13,2 \%$ dan pada usia 25-34 tahun dengan jumlah penderita hipertensi $20,1 \%$ selanjutnya pada usia 35-44 tahun sejumlah $31,6 \%$ dan pada usia $45-$ 54 tahun jumlah penderita hipertensi semakin meningkat dengan jumlah $45,3 \%$ dan pada usia 55-64 tahun dengan jumlah 55,2\% penderita hiertensi sedangkan pada usia 65-74 tahun sebanyak $63,2 \%$ dan pada usia $75 \mathrm{ke}$ atas sebesar 69,5\% penderita hipertensi (Kemenkes RI, 
2018). Berdasarkan Profil kesehatan Sulawesi

Selatan tahun 2016 sebanyak 21,90\% dengan kasus tertinggi di kabupaten selayar dengan jumlah 32,49\% penderita hipertensi selanjutnya kabupaten soppeng $24,92 \%$, dan kabupaten takalar $14,825 \%$ penderita penyakit hipertensi (Profil Dinkes Sulsel, 2017)

Berdasarkan data Puskesmas Pertiwi Kota Makassar tahun 2020 terdapat kasus hipertensi sebanyak 50 orang yang mengalami penyakit hipertensi dan dikategorikan lansia dan bukan lansia. Jumlah lansia yang mengalami penyakit hipertensi sebanyak 28 orang.

\section{BAHAN DAN METODE}

Jenis penelitian yang digunakan adalah penelitian kualitatif dengan menggunakan pendekatan studi kasus. Penelitian ini dilaksanakan pada bulan Agustus 2020 di Puskesmas Pertiwi Kota Makassar Sulawesi selatan. Penentuan subjek penelitian dengan menggunakan purposive sampling yaitu semua lansia yang berdomisili di wilayah kerja Puskesmas Pertiwi Kota Makassar dengan kriteria lansia yang menderita penyakit hipertensi beberapa bulan terakhir di wilayah kerja Puskesmas Pertiwi Kota Makassar, dan bersedia diwawancarai. Teknik pengumpulan data dengan cara pengamatan langsung (observasi), wawancara mendalam (Interview Guide) dengan menggunakan alat perekan suara (HP), pedoman wawancara, alat tulis, catatan lapangan serta data yang diperoleh dari peneliti minta melalui petugas kesehatan yang bekerja di puskesmas Pertiwi Kota Makassar Provinsi Sulawesi Selatan. Pengecekan keabsahan data dengan cara melakukan triagulasi sumber, triagulasi waktu dan triagulasi teknik

\section{HASIL}

\section{Karakteristik Informan}

Informan dalam penelitian ini adalah masyarakat yang berobat di Puskesmas Pertiwi Kota Makassar. Karakteristik informan mencakup inisial, umur, jenis kelamin. Informan yang berhasil diwawancarai oleh peneliti berjumlah 9 orang yang terdiri dari 2 laki-laki dan 7 perempuan rata-rata berusia 60-70 $>$ tahun.

\section{Hasil Penelitian}

Dari hasil wawancara mendalam (indepth interview) terhadap informan pada saat penelitian, maka dibuatlah kerangka hasil penelitian sebagai berikut:

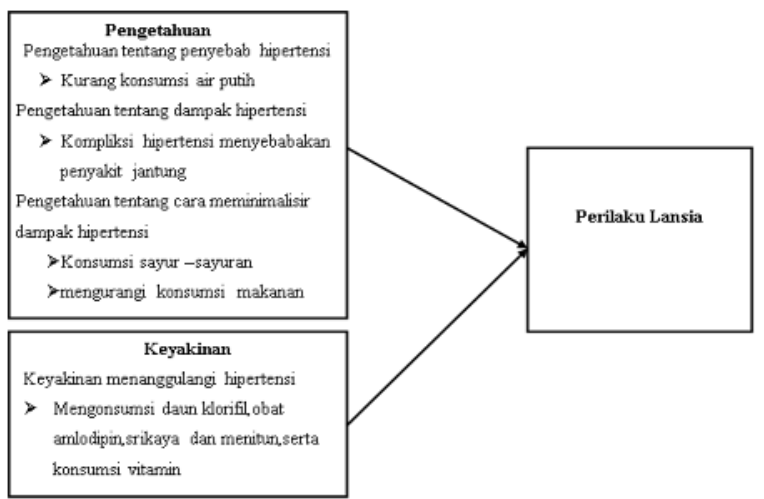

Gambar 1. Kerangka Hasil Penelitian (Yustinus, 2020)

Berdasarkan hasil penelitian yang dilakukan informan mengenai perilaku lansia dalam upaya penanggulangan hipertensi di wilayah kerja Puskesmas Pertiwi, diperoleh hasil 
bahwa untuk aspek pengetahuan informan terdiri atas pengetahuan tentang dampak hipertensi dan pengetahuan tentang cara memanilisir dampak hipertensi.

Menurut informan dampak hipertensi menyabakan gangguan kejiwaan, dan penyakit jantung, sedangkan untuk cara meminimalisir dampak hipertensi dilakukan dengan mengonsumsi sayur-sayuran, mengurangi makanan berlemak, dan sering berolahraga. Selain dari aspek pengetahuan, diperoleh juga informasi mengenai aspek keyakinan. Informan meyakini bahwa dengan mengonsumsi obat klorifil, srikaya dan mentimun, serta mengonsumsi vitamin diyakini mampu menanggulangi penyakit hipertensi.

Pengetahuan adalah salah satu hal yang paling penting dalam pembentukan perilaku seseorang, dalam penelitian ini, pengetahuan informan meliputi pengetahuan tentang penyebab hipertensi mengakibatkan karena kurang konsumsi minum air putih sedangkan. Menurut informan lain juga mengatakan bahwa pengetahuan tentang dampak penyakit Hipertensi juga mengakibatkan jantung Adapun Pengetahuan informan tentang cara meminimalisir dampak hipetensi dilakukan dengan cara mengonsumsi sayur-sayuran, kurangi makanan berlemak, sering berolahraga.

$$
\text { Pengetahuan pada lansia juga }
$$

berpengaruh kepada keyakinan seseorang. Keyakinan penderita hipertensi agar meningkatkan keyakinan diri dengan aktif menggali informasi yang berkaitan dengan hipertensi khususnya bagi penderita hipertensi pada lansia yang mempengaruhi perilaku seseorang. Dalam penelitian informan meyakini bahwa dengan mengonsumsi obat klorifil, srikaya dan mentimun, serta mengonsumsi vitamin mampu menanggulangi penyakit hipertensi.

\section{Kategorisasi Penelitian Atau Uraian Penelitian}

\section{Pengetahuan tentang penyebab hipertensi}

Berdasarkan hasil wawancara mendalam kepada informan tentang pengetahuan penyebab hipertensi, diperoleh informasi bahwa penyakit hipertensi dapat disebabkan karena kurang mengonsumsi air putih. Menurut informan kurangnya konsumsi minum air putih dapat menjadikan darah yang lebih kental. Hal inilah yang dianggap sebagai pemicu terjadinya penyakit hipertensi, seperti yang diungkapkan oleh informan sebagai berikut

"saya dibilang kurang minum air putih jadi saya darahku kental karena kurang minum air putih "( HSDT 17 september 2020)

\section{Pengetahuan tentang dampak hipertensi}

Berdasarkan hasil wawancara mendalam terhadap informan tentang pengetahuan dampak hipertensi, diperoleh informasi bahwa penyakit hipertensi juga dapat menyebakan penyakit jantung. Hal ini sejalan dengan apa yang di ungkapkan oleh informan dibawah ini:

"..Saya sering periksa tensiku tinggi anu saya juga Jantug. "(AR 17 september 2020) 


\section{Pengetahuan tentang cara meminimalisir dampak hipertensi}

Berdasarkan hasil wawancara mendalam dengan informan tentang cara meminimalisir dampak hipertensi diperoleh informasi bahwa penyakit hipertensi dapat diatasi dengan cara mengonsumsi sayur-sayuran. Seperti yang di ungkapkan oleh informan sebagai berikut

“..Banyak konsumsi sayur-sayuran..”(AN, 17 september 2020)

Setelah dilakukan wawancara dengan informan, diperoleh hasil wawancara bahwa untuk meminimalisir dampak hipertensi dapat dilakukan dengan cara sering melakukan aktivitas seperti berolahraga yang cukup. Seperti yang diungkapkan oleh informan dibawah ini :

“..Ndak habis kalau saya sering olahraga itu cuman jalan kaki.." ( DT 17 September 2020)

\section{Keyakinan Tentang Menanggulangi Penyakit Hipertensi}

Berdasarkan hasil wawancara dengan informan dapat diperoleh informasi bahwa penyakit hipertensi diyakini dapat diatasi dengan cara mengkonsumsi daun klorifil. Seperti yang diungkapkan oleh informan sebagai berikut:

“..Iya, itu daun klorifil yang banyak dijalan itu untuk menurunkankolestrol,dan tekanan darah tinggi.."(MM 17 september 2020)

Selain daun klorifil yang diyakini dapat mengurangi tekanan darah tinggi. Setelah dilakukan wawancara mendalam diperoleh informasi bahwa obat amlodipin dapat mengurangi penyakit tekanan darah tinggi. Seperti tang diungkapkan informan berikut ini:

"..Oh, itu amlodipin atau apakah itu.." (HSDT. 17 September 2020)

Selain obat daun klorifil dan amlodipin. Setelah dilakukan wawancara mendalam dengan informan diperoleh dari informasi bahwa mengkonsumsi daun srikaya dan mentimun serta konsumsi vitamin di yakini bahwa dapat menurunkan tekanan darah tinggi. Seperti yang ungkapan oleh kedua informan dibawah ini:

"Daun itu srikaya belanda dan mentimun saya rebus saya minum dan konsumsi vitamin"( DT. AN 17 September 2020)

\section{PEMBAHASAN}

Dari hasil wawancara yang diperoleh dari informan maka dibuat suatu pembahasan setiap variabel yang diteliti sebagai berikut:

\section{Pengetahuan Tentang Penyebab Hipertensi.}

Menurut Bayuwangi dalam buku Priyoto tentang UU kesehatan nomor 23 Tahun 1992 pasal 19 ayat 1 mengatakan bahawa" usia lanjut (growing old) faktor yang mempengaruhi perilaku adalah pengetahuan seseorang lanjut usia mengalami perubahan biologis, fisik, sikap, perubahan yang mempengaruhi pada keseluruhan aspek kehidupan termasuk kesehatan".

Berdasarkan hasil wawancara mendalam kepada informan tentang pengetahuan penyebab 
hipertensi, diperoleh informasi bahwa penyakit hipertensi dapat disebabkan karena kurang mengonsumsi air putih.

Berbedah dengan hasil peneliti dari (Hanif et al.,2014) mengatakan bahwa kurangnya olahraga pada lansia akan menyebabkan hipertensi. Kurangnya olahraga lansia disebabkan oleh faktor usia. Lansia lebih banyak duduk, kurang gerak, dan gaya hidup santai. Ini akan mengakibatkan kurangnya aktifitas fisik sehingga jantung tidak terlatih, pembuluh darah kaku, sirkulasi darah tidak mengalir dengan lancer, dan menyebabkan kegemukan. Faktor inilah yang menyebabkan terjadinya hipertensi

\section{Pengetahuan Tentang Dampak Hipertensi.}

Menurt Notoatmodjo (2010 dalam Irwan, 2017) menyatakan bahwa salah satu faktor yang menyebabkan terjadinya perubahan prilaku kesehatan adalah faktor predisposisi (predisposing factor) yang didalamnya termasuk pengetahuan tentang diet hipertensi

Dari hasil wawancara mendalam terhadap informan tentang pengetahuan dampak dari komplikasi hipertensi sebabkan jantung seperti yang di ungkapkan oleh informan

Penelitian ini sejalan dengan (Nuraini 2015) dampak penyakit hipertensi penyakit jantung, gagal jantung kongesif, stroke, gangguan penglihatan dan penyakit ginjal. Tekanan darah yang tinggi umumnya meningkatkan resiko terjadinya komplikasi tersebut. Hipertensi yang tidak diobati akan mempengaruhi semua sistem organ dan akhirnya memperpendek harapan hidup sebesar 10-20 tahun. Mortalitas pada pasien hipertensi lebih cepat apabila penyakitnya tidak terkontrol dan telah menimbulkan komplikasi ke beberapa organ vital. Sebab kematian yang sering terjadi adalah penyakit jantung tanpa disertai stroke dan gagal ginjal.

\section{Pengetahuan Tentang Meminimalisir Dampak Hipertensi}

Cara

Menurut WHO dalam Putri et al., 2018) mengatakan bahwa mencegah dan mengontrol tekanan darah dengan mengurangi dan mengendalikan stres, makanan yang sehat yang terdiri dari banyak buah dan sayuran segar yang menyediakan nutrisi seperti potassium dan serat, membatasi asupan natrium, menyadari bahwa banyak makanan olahan yang tinggi garam, gula, kopi dan minuman keras

Berdasarkan hasil wawancara mendalam yang diperoleh dari informan tentang cara memanilisir dampak hipertensi bahwa dengan Konsumsi sayur menurunkan hipertensi seperti yang di ungkapkan oleh informan.

Berdasarkan hasil penelitian dari Putri et al., 2018) sejalan dengan penelitian sebelumnya dia mengatakan bahwa konsumsi Sayur juga memiliki kandungan serat, kalium dan magnesium yang dapat menurunkan tekanan darah. Mekanisme serat, magnesium dan kalium dalam menurunkan tekanan darah sudah dijelaskan dalam riwayat konsumsi buah 
terhadap kejadian hipertensi. Hubungan

Menurut (Almatsier, 2009 dalam

Septiana, 2015) adalah keadaan tubuh sebagai akibat konsumsi makanan dan penggunaan zatzat gizi, yang dibedakan antara status gizi buruk, kurang, baik, dan lebih. Sejalan dengan teori dari (Jansen, 2006). Yang mengatakan bahwa Konsumsi makanan yang berlemak dapat menyebabkan tekanan darah meningkat. Konsumsi lemak yang berlebihan akan meningkatkan kadar kolesterol dan tekanan darah terutama kolesterol dan Timbunan lemak yang disebabkan oleh kolesterol akan menempel pada pembuluh darah yang lama-kelamaan akan terbentuk plaque. Terbentuknya plaque dapat menyebabkan penyumbatan pembuluh darah atau aterosklerosis. Pembuluh darah yang terkena aterosklerosis akan berkurang elastisitasnya dan aliran darah ke seluruh tubuh akan terganggu serta dapat memicu meningkatnya volume darah dan tekanan darah. Meningkatnya tekanan darah tersebut dapat mengakibatkan terjadinya hipertensi

Berdasarkan hasil wawancara yang dilakukan, diperoleh informasi bahwa sala satu yang di ketahui oleh informan mengenai cara memanilisir dampak dari hipertensi dengan cara mengurangi konsumsi berlemak seperti hasil ungkapan informan

Berbedah dengan hasil penelitian Menurut Hembing, dalam Fatonah \& Hernawilly, 2012) mengatakan bahwa cara untuk menurunkan tekanan darah tinggi, yaitu dengan terapi menggunakan jus buah- buahan tertentu dan ramuan tradisional atau disebut back to nature. Antara lain menggunakan jus mengkudu, seledri (Apium graviolens) dan belimbing manis. Cara pembuatannya, satu buah mengkudu matang dan satu buah belimbing manis yang dijus. Lalu jus tadi direbus dengan 250 cc air sampai mendidih. Air rebusannya diminum dalam keadaan hangat sebanyak segelas setiap pagi atau malam hari; Ada juga yang mengombinasikan antara dua buah mengkudu matang, satu buah belimbing manis dan 100 gr seledri, ketiga bahan tadi dijus, lantas campuran jus yang dihasilkan direbus dengan air $250 \mathrm{cc}$ sampai mendidih dan ditambahkan madu secukupnya. Lalu diminum dalam keadaan hangat sebanyak satu gelas pada pagi atau malam hari.

Kwick dalam Notoatmodjo, dalam buku Irwan, 2017) "perilaku adalah "tindakan atau perbuatan organisme yang dapat diamati dan bahkan dapat dipelajari" Motif merupakan salah satu faktor yang mempengaruhi atau penyebab timbulnya perilaku dalam hal ini sejalan dengan teori Winardi mengemukakan bahwa motif-motif merupakan "mengapa" dan "perilaku" mereka muncul dan mempertahankan aktifitas dan determinasi arah umum perilaku seorang individu. Pada intinya dapat dikatakan bahwa motif-mitif atau kebutuhan merupakan penyebab terjadinya tindakan-tindakan-Kekuatan merupakan alasan yang melandasi perilaku, kekuatan motif cenderung menyusut, apabila ia 
terpenuhi atau apabila terhalangi. Berdasarkan hasil wawancara yang dilakukan, diperoleh dari informasi bahwa salah satu faktor memanilisir dampak hipertensi menurut informan bahwa dia mengatakan Sering berolaragah dengan melakukan aktivitas seperti yang diungkapkan oleh informan tersebut.

Berdasarkan hasil penelitian Rusiani, 2017) sejalan dengan hasil penelitia sebelumnya Mengatakan bahwa Olahraga aerobik, seperti bersepeda, jogging, dan berjalan kaki yang teratur dapat memperlancar peredaran darah sehingga dapat menurunkan tekanan darah setiaporang aktif melakukan kegiatan fisik cenderung mempunyai frekuensi denyut jantung yang lebih tinggi. Hal tersebut mengakibatkan otot jantung bekerja lebih keras pada setiap kontraksi. Makin keras usaha otot jantung dalam memompa darah, makin besar pula tekanan yang dibebankan pada dinding arteri sehingga meningkatkan tahanan perifer yang menyebabkan kenaikkan tekanan darah. Kurangnya aktifitas fisik juga dapat meningkatkan risiko kelebihan berat badan yang akan menyebabkan risiko hipertensi meningkat.

\section{Keyakinan Dalam Menanggulangi Penyakit Hipertensi}

\section{Menurut WHO (World Health}

Organization). Dunia internasional, penggunaan obat tradisional sangat mudah dan sudah berkembang dan meningkat, khususnya dikalangan masyarakat dasar sejak dikeluarkannya Deklarasi Alma-Ata tahun 1978 dengan program pengobatan tradisional Keseriusan pemerintah mendukung pemanfaatan obat tradisional yang dilihat peraturan yang ada, terutama sejak dikeluarkannya Peraturan Menteri Kesehatan tentang Saintifikasi Jamu pada tahun 2010 (Delima et al, 2012).

Berdasarkan hasil wawancara dengan informan diperoleh informasi bahwa informan dapat diatasi penyakit hipertensi dengan meyakini bahwa hipertensi dapat diatasi dengan cara mengkonsumsi daun klorifil.

Hal ini Sejalan dengan hasil penelitian dari Sabilla 2016 dalam Ibrahim et al., 2016) yang mengatakan bahwa cincau sudah dikenal oleh masyarakat sebagai pangan penurunan panas (demam), mual, obat radang lambung,batuk dan penurunan tekanan darah tinggi. Daun Cyclea barbata Miers diketahui mengandung klorofil, serta senyawa bioaktif flavonoid dapat memberikan efek vasodilatasi terhadap pembuluh darah yang membantu melindungi fungsi jantung dan flavonoid juga dapat menurunkan kekuatan arteri.

Berdasarkan hasil survey (Ibrahim, Arman, and Putri 2016) pada penelitian yang dilakukan pada 17 April 2018 dengan mewawancarai 10 orang pasien Hipertensi yang berkunjung ke Wilayah Kerja Puskesmas Andalas diketahui bahwa 6 orang pasien hipertensi tidak mengetahui manfaat dan kegunaan dari perasan air daun cincau hijau untuk penurunan tekanan darah yang mereka 
tahu jika tekanan darah naik, mereka minum obat saja dan 4 orang mengatakan mengetahui tentang air rebusan daun cincau hijau tetapi karena malas mencarinya maka mereka tidak meminumnya sebagai perubahan gaya hidup diduga meningkatkan faktor risiko hipertensi.

Menurut Pebrianti (2013 dalam K Rama

Nur Kurniawan et al., 2019) mengartikan bahwa keyakinan seseorang dapat dilihat dan diketahui sejauh mana seseorang percaya dan memiliki keahlian didalam bidang apapun untuk melakukan aktivitas secara efektif agar mencapai tujuan-tujuan yang ingin diperoleh

Selain daun klorofil yang diyakini dapat mengurangi tekanan darah tinggi. Setelah dilakukan wawancara mendalam diperoleh informasi bahwa obat amlodipin dapat mengurangi penyakit tekanan darah tinggi.

Hal ini Sejalan dengan hasil penelitian Dharma (2017) dalam Taslim \& Betris (2020) mereka meyakini bahwa dengan konsumsi obat Amlodipin memiliki kelebihan dibandingkan dengan obat hipertensi lainnya karena efisien dalam pemberian yaitu cukup satu kali sehari, akan menurunkan tekanan darah secara perlahan dan absorbsinya sempurna dalam tubuh, terutama bagi penderita berusia.

Menurut Koenig, 2001 dan Killbourne et al 2009 dalam Munawara, 2017). Pada dasarnya, salah satu faktor yang mempengaruhi tekanan darah adalah religiusitas. Religiusitas adalah ekspresi spiritual seseorang yang berkaitan dengan system keyakinan, nilai, simbol dan ritual. Hal tersebut berarti bahwa religiusitas pada umumnya memiliki aturan-aturan yang harus dipatuhi dan dilaksanakan yang berfungsi untuk mengikat seseorang dalam hubungan dengan Tuhan, sesama manusia dan alam sekitar Selain obat daun klorifil dan amlodipin. Setelah dilakukan wawancara mendalam dengan informan diperoleh dari informasi bahwa mengkonsumsi daun srikaya dan mentimun serta konsumsi vitamin di yakini bahwa dapat menurunkan tekanan darah tinggi.

Sedangkan Menurut hasil penelitian (Paramita et al.,2017) dari hasil penelitiannya dia menemukan ada 9 tumbuhan obat yang digunakan sebagai terapi komplementer hipertensi. Seluruh tumbuhan obat tersebut memang memiliki dasar teori yang kuat untuk efek antihipertensi. Daun sirsak merupakan obat bahan alam yang paling sering digunakan, disusul oleh rosella, seledri, alfalfa, kulit manggis, daun salam, mentimun, buah mengkudu dan jintan hitam. Hasil penelitian ini sedikit berbeda dengan penelitian oleh Pujianto (2008) Tumbuhan obat yang diminum untuk menurunka tekanan darah tingi adalah sirih, mahkota dewa, salam, kecapi, mustajab, kumis kucing, keji beling, ceplukan, belimbing dan mentimum

Menurut Niven (2008 dalam Nati, N.D.) mengatakan bahwa salah satu faktor yang mempengaruhi kepatuhan adalah keyakinan diri (self efficacy). Keyakinan merupakan dimensi spiritual yang dapat menjalani kehidupan. 
Penderita hipertensi yang berpegang teguh terhadap keyakinan nya memiliki jiwa yang tabah dan tidak mudah putus asa serta dapat menerima keadaannya, demikian juga cara perilaku yang lebih baik

Berbedah dengan hasil penelitan (K, Rama Nur Kurniawan et al., 2019) mengatakan bahwa, masyarakat meyakini penyakit hipertensi dapat diatasi dengan cara mengonsumsi makanan yang alami, berolahraga secara teratur, serta membiasakan berdoa sebelum makan.

\section{KESIMPULAN DAN SARAN}

Dari hasil penelitian mengenai Perilaku lansia dalam upayah penanggungalang hipertensi di Wilayah Kerja Puskesmas Pertiwi Makassar diperoleh kesimpulan bahwa pengetahuan informan tentang penyebab hipertensi diakibatkan karena kurangnya mengonsumsi air putih sehingga menyebabkan penyakit jantung. Untuk meminimalisir dampak hipertensi yaitu dengan mengkonsumsi sayur dan sering berolaraga. Selain itu Informan meyakini bahwa penanggulangan hipertensi dengan cara konsumsi daun klorifil, obat amlopidin, srikaya dan mentimun serta konsumsi vitamin.

Di harapkan kepada lansia penderita hipertensi agar meningkatkan pengetahuan tentang cara meminimalisir hipertensi dengan cara rajin konsumsi minum air putih, konsumsi sayur-sayuran, dan berolahraga dengan teratur serta meningkatkan konsumsi obat herbal seperti srikaya dan mentimun, daun klirifil, obat amlodipin serta vitamin.

\section{DAFTAR PUSTAKA}

Profil Dinkes Sulsel. (2017). Provinsi Sulawesi Selatan Tahun 2016.

Mia A. 2019. “Faktor-Faktor Yang Berhubungan Dengan Konsumsi Mie Instan Pada Mahasiswa Stikes Perintis Padang Tahun 2019.'”

Fatonah, Siti, And Hernawilly. 2012. "Perilaku Pemilihan Obat Tradisional Untuk Menurunkan Tekanan Darah Pada Lansia Di Kota Bandar Lampung." Jurnal Keperawatan viii(1): 1-9.

Hanif, Siregar Abdul, Syarif Zen Yahya, And Surita Ginting Jurusan. 2014. "FaktorFaktor Penyebab Terjadinya Hipertensi Pada Lansia Di Upt Pelayanan Sosial Lanjut Usia Anak Dan Balita Binjai Dan Medan Tahun 2014.” 9(2): 128-33. Http://Ojs.Poltekkes-

Medan.Ac.Id/Pannmed/Article/Download/2 93/233.

Heriyand, Kartini Hasballah, And Teuku Tahlil. 2017. "Pengetahuan, Sikap, Dan Perilaku Diet Hipertensi Lansia Di Aceh Selatan." Jurnal Ilmu Keperawatan 6(1).

Herlinah, Lily, Wiwin Wiarsih, And Etty Rekawati. 2013a. "Hubungan Dukungan Keluarga Dengan Perilaku Lansia Dalam Pengendalian Hipertensi." Keperawatan Komunitas 1(2): 108-15.2013b. "Hubungan Dukungan Keluarga Dengan Perilaku Lansia Dalam Pengendalian Hipertensi." Jurnal Keperawatan Komunitas 1(2): 108-15.

Ibrahim, Eliza Arman, And Widia Permata Putri. 2016. "Pengaruh Perasan Air Daun Cincau Hijau (Cyclea Berbata Miers) Terhadap Tekanan Darah Pada Penderita Hipertensi Di Wilayah Kerja Puskesmas Andalas." Tinjauan Sosial, Etika Dan Hukum 
Surrogate Mother Di Indonesia 7(2): 10813.

Irwan. 2017. Etika Dan Perilaku Kesehatan. Yogyakarta.

Kesehatan, Kementerian Kesehatan Badan Penelitian Dan Pengembangan. 2018. Hasil Utama Riskesdas 2018.

Kiik, Stefanus Mendes, Junaiti Sahar, And Henny Permatasari. 2018. "Peningkatan Kualitas Hidup Lanjut Usia (Lansia) Di Kota Depok Dengan Latihan Keseimbangan.” 21: 109-16.

Konna, Suryanti. 2017. Universitas Hasanuddin "Hubungan Kesehatan Mental Dan Healthy Food Choice Dengan Kejadian Hipertensi Pada Guru Sekolah Menengah Di Makassar Tahun 2017." Universitas Hasanuddin.

Kurniawati, Sandra Aprilia. 2017. "Hubungan Pengetahuan Dengan Perilaku Pola Makan Lansia Yang Menderita Hipertensi."

Masyudi. 2018. "Faktor Yang Berhubungan Dengan Perilaku Lansia Dalam Mengendalikan Hipertensi.” 3(1): 57-64.

Muh, La Ode Et Al. 2020. "Hubungan Gaya Hidup Dengan Kejadian Hipertensi Pada Lansia Di Wilayah Kerja Puskesmas MeoMeo Kota Bau Bau." Jurnal Industri Kreatif (Jik) 4(01): 45-56.

Munawara, Dwi Januasti. 2017. "Naskah Publikasi Disusun Oleh: Dwi Januasti Munawara 201210201094."

Murniati. 2017. "Hubungan Antara Sikap Tentang Pencegahan Kekambuhan Dengan Kepatuhan Menjalankan Diit Hipertensi Pada Lansia Di Posyandu Bagas Waras Pabelan Kartasurahubungan Antara Sikap Tentang Pencegahan Kekambuhan Dengan Kepatuhan Menjalankan Diit Hipertensi Pada Lan."

Nati, Nikadek Noviani Rambu. "Hubungan
Antara Keyakinan Diri Dengan Kepatuhan Diet Pada Penderita Hipertensi Di Puskesmas Lerep."“No Title.” 2015.

Nubatonis, Robinson. 2015. "Hubungan Perilaku Lansia Dengan Kejadian Hipertensi Di Puskesmas Nglegok Kabupaten Blitar."

Nuraini, Bianti. 2015. "Risk Factors Of Hypertension." 4(5): 10-19.

Paisey, Ave Winny P. 2017. "Profil Penderita Hipertensi Yang Berobat Jalan Di Puskesmas Sanggeng Manokwari Juli Sampai September 2017."

Paramita, Swandari Et Al. 2017. "Pola Penggunaan Obat Bahan Alam Sebagai Terapi Komplementer Hipertensi Adalah Suatu Keadaan Ketika Tekanan Darah Di Pembuluh Darah Meningkat Secara Kronis - Hal Tersebut Dapat Terjadi Karena Jantung Bekerja Lebih Keras Memompa Darah Untuk Memenuhi Kebutuh.” 1(7).

Prassetyawan, Danu. 2016. "Gambaran Persepsi Perilaku Self Care Pada Lansia Dengan Hipertensi Di Padukuhan Medari Gede Caturharjo Sleman."

Putri, Amanda Widiya, M Dawam Jamil, And Lulu Fathnatul Ulya. 2018. "Hubungan Riwayat Konsumsi Sayur Dan Buah Serta Air Minum Dengan Kejadian Hipertensi Pada Lansia Di Kabupaten Bantul." : 20.

Ramli, Rahmawati, And Masyita Nurul Fadhillah2. 2020. "Faktor Yang Mempengaruhi Fungsi Kognitif Pada Lansia." Window Of Nursing Journal 01(01): 23-32.

Riyadina, Woro. 2019. Hipertensi Pada Wanita Menopause. Ed. : Fadly Suhendra Dan Tantrina Dwi Aprianita. Jakarta: Lipi Press.

Riyadina, Woro, Evi Martha, And Athena Anwar. 2019. "Perilaku Pencegahan Dan Pengendalian Hipertensi : Studi 


\section{JURNAL Promotif Preventif}

p-ISSN: $2622-6014$

Vol. 4 No. 1 Agustus 2021, Hal. 39 - 50

http://journal.unpacti.ac.id/index.php/JPP

Pengetahuan, Sikap, Perilaku (PSP) Dan Kesehatan Lingkungan Pada Wanita Pasca Menopause Di Kota Bogor." Perilaku Pecegahan Dan Pengendalia Hipertensi: 182-96.

Rusiani, Hanna. 2017. "Gambaran Pola Konsumsi Pada Lansia Penderita Hipertensi."

Sari, Vivi Indah, Achmad Herman, And Ahmad Yani. 2018. "Perilaku Lansia Dalam Mencegah Penyakit Hipertensi Di Kelurahan Besusu Barat Wilayah Kerja Puskesmas Singgani Kota Palu." : 389-94.

Setyanto, Wildan. 2017. "Hubungan Aktivitas Fisik Dengan Kejadian Hipertensi Pada Lansia."
Sidik, Abu Bakar. 2018. "Pengalaman Lansia Dalam Mengatasi Nyeri Kepala Pada Penyakit Hipertensi Di Panti Sosial Tresna Werdha Sumatera Selatan Tahun 2016." Jurnal Ilmiah Multi Science Kesehatan 8: 122-34.

Sinaga, Anni. 2014. "Hubungan Dukungan Keluarga Dengan Pencegahan Hipertensi Pada Lansia Di Desa Sukamaju Wilayah Binaan Uptd Cikalong Kecamatan Cimaung.": 39-46.

Taslim1, Tuty, And Yani Anggela Betris. 2020. "Gambaran Pemberian Obat Pada Penderita Overview Of Drugs In Patients With Hypertension." 2(2): 72-79. 